\title{
Collection preservation news
}

\section{Collection protection issues in a library renovation project}

\author{
by Eric MacDonald
}

B

uilding renovation projects present particular challenges to libraries. One of the greatest challenges is to protect the library's collections while much or all of the building is in a state of semi-chaos.

The purpose of this article is to call attention to some of the important collection protection issues that need to be considered during a library renovation project. It will demonstrate the importance of including a person responsible for collection protection in the project direction team. The article is based on the seismic retrofit and renovation project of the Main Library at the University of California, Irvine (UCI), from 1996 to 1997.

To prepare for the project, the library selected a project coordinator in late 1994; in early 1995 the library appointed a committee to work with the coordinator on all aspects of planning and implementation. This group stayed with the project throughout.

\section{Planning and initial stages of the project}

Collection protection demands particular attention from the beginning. As Preservation Librarian for the UCI library, I was asked to be part of the project coordinating committee and served on it throughout the project. Since there are so many issues related to collection care in any library build- ing renovation project, the presence of a person able to carry this responsibility on the planning committee is important to make sure that these issues are addressed in a timely manner.

A Request for Proposal (RFP) document codifies the initial planning and specifications for the project. The RFP details the parameters of the project and is sent to contractors interested in bidding on the project. Collection protection provisions, such as collection removal and protection against dust damage, must be written into the RFP so that prospective bidders understand that these are important issues for the library, and so that funding can be included in the bids.

Once the contractor is selected, the presence of a collections person in the group of people who meets regularly with the contractor to discuss the project is vital. In the construction meetings, details of the project are discussed and many crucial decisions are taken.

Collection removal. One of the first planning issues that needs to be discussed is whether to move books out of the construction area. Dust is an inevitable by-product of any construction project, and books are great collectors of dust. Consequently, it is necessary to determine how many books may be 
affected and whether they can be isolated to protect them from construction dust. If they cannot be left in place, then it must be determined how many will have to be moved and where they will go.

Patron access contributes to this decisionmaking process. Relocations are typically round trip: money must be allocated for the return of the books as well as for their removal from the building.

It is possible to undertake certain types of book moves with internal resources. For relocations of modest size, use student labor and rent large, wooden book-moving carts and vans to transport the materials on the carts. However, for larger moves, or for those involving unique, highly valuable or fragile items, professional help should be sought.

Special collections materials. Because of their rarity and high value, special collections materials must be given extra attention in all aspects of planning for a renovation project, especially regarding their location during demolition and construction. Even if some or all of the regular stacks collection is to be kept on site during the project, serious consideration should be given to moving the special collections materials away from the building site. In addition to being at risk from dust and the possible lack of climate control for the duration of the project, any serious accident during the project could also put the special collections materials at risk. It is a good idea to hire professional movers for these materials.

Microforms. Microform and other media materials can also present a special challenge. Because of the danger of abrasive construction dust getting onto the film, if these materials remain on site, they should be kept in their cases as far away as possible from the actual construction work. Microform cabi-

\section{Issues for collection protection}

- Collection protection officer

- Dust protection

- Collection removal

- Special collections and media

- Mold prevention measures

- Portable A/C units

- Collection cleaning nets kept on site should not be taped or covered with plastic sheeting, since damaging humidity could be trapped inside. The location of feature film and videotape collections will depend on several factors including their proximity to the demolition and construction work and the need for patrons to access the materials during the project. Certainly they should not be left in the building if proper environmental conditions cannot be guaranteed.

Good records need to be kept to make sure that patrons and staff know where the materials are. The earlier the planning for this work is done, the better.

Publicity is important to let patrons and members of the institution know about the plans and progress of the project. Some of the ways in which collections-related issues can be brought to peoples' attention during the project include signage, newsletters, Web sites, and school newspapers (where applicable).

Construction dust. Because of its abrasive quality and because of the large quantities generated, construction dust can be damaging to the collections. Dust is a problem throughout any project, but particularly during the initial demolition stage. Additionally, construction dust left on the books after the project can be annoying and possibly harmful to patrons.

The library project team must demand that the best precautions be taken against dust getting into the collection. It is not sufficient simply to hang plastic sheets around the construction areas. Dust can easily get around hanging plastic, but draping the stacks in plastic sheeting may help. If stack draping is done, the plastic sheeting should not extend to the floor, except for short periods of time. Closing the books off from air circulation for long periods of time can lead to mold growth in the hot and stagnant air trapped uncler the plastic sheets.

HVAC system. Leaving part or all of the HVAC (heating, ventilation, and air conditioning) system on can be helpful to the climate control in the book stacks areas during the project. However, it can transport dust throughout the building. If it is turned off, then the crews in the work areas will probably need fans. These fans will contribute to the spread of dust. 
Most likely the HVAC system will have to be turned off because the contractors will require access to it or because renovating it may be part of the project. In this case, it will be necessary to make alternative arrangements to ensure air circulation and the proper relative humidity and temperature conditions during the project. One such alternative is to rent portable air conditioning units and place them throughout the building in the stacks areas. For such units, it is necessary to have people empty their water collection tanks every day.

\section{During the project}

The person responsible for collections issues needs to be part of the library team that meets on a regular basis with the contractor. The presence of this person in the construction meetings is in itself a reminder that the library values its collection and wants to ensure that its protection is a primary consideration throughout the project. Many issues that have a bearing on the safety of the collection come up at these meetings and it is important to be on hand to deal with them

Many unforeseen things can happen during any construction project, especially if there is demolition involved. Problems arising from such surprises are compounded by ongoing concerns about air circulation, relative humidity, and temperature in the building.

The presence of collections remaining in areas affected by the construction calls for frequent monitoring of the building. One method is to walk the building and check the temperature and humidity conditions with a hand-held measuring device. The readings may not be precise, but they will allow one to ascertain if there were any sustained conditions of high temperature or humidity

Collection security. If books are to be left in the building during the project, then working with the contractor to ensure their security is vital. The value of the collections, and their potential vulnerability to theft or damage from workers on site and from unauthorized people gaining access to the site during the project, needs to be impressed upon the contractor. Regular inspection tours can help to ensure collection security

\section{After the project is completed}

Any collections that had to be moved off site will have to be returned to the building. Ensuring careful handling of the collections during this process is important.

\section{Collection cleaning will be high on the}

list of post-project issues. Despite the best efforts to protect collections, it is likely that dust will penetrate them and that collection cleaning will have to be done. This cleaning project must include the shelves, too, not just the books. Professional library collection movers will generally be able to provide this service. However, it can be rather expensive. An alternative is to mount an in-house cleaning project.

At the University of California, Irvine, we undertook such a project that systematically went through the entire collection of 855,000 volumes in the circulating stacks and reference collections; 54,000 special collections volumes; and 10,000 linear feet of government documents. Using student workers, we were able to complete the entire project in five months for about $\$ 35,000$.

We used HEPA vacuum cleaners on the majority of the volumes and special dust cloths on the special collections materials. We cleaned both the books (each individual volume) and the shelves. The easiest and most cost-effective cleaning was that done for the regular volumes. The careful work required for the special collections materials was more time consuming and costly. (We had chosen to store some of our special collections materials on site in a specially isolated area. Nevertheless, these materials did get dusty enough to require cleaning.)

\section{Conclusion}

Collection protection concerns need to be a major factor in planning for and undertaking any library renovation project. The library's collection must be protected from a variety of threats if it is to emerge intact at the conclusion of the project. Although collection protection may be obvious to most of the library staff, this perspective may not be apparent to non-library people. People within the organization but outside the library (for example, design and construction or business office folks

(continued on page 282) 
when it comes to identifying and locating information sources.

\section{Librarians as cyberpilots}

Like pilots, librarians receive special training and instruction in using specialized equipment and in performing complicated tasks. Although we are not involved in the life-and-death situations that are the daily trade of pilots, like them, we find that much of our success is based on skill and intuition.

Service and duty ethics are as strong among librarians as among the military. We train and practice on information flight simulators before going out with real passengers or cargo. We pick up hot information spots on our radar and log them for others to find; we are continually mapping and expanding our cybernetic horizons and destinations. We rely heavily on a ground crew of support staff who provide the infrastructure we need to do our work and we rely on the information traffic controllers in our organizations who serve as team leaders and department heads.

We conduct our pre-flight briefings by discussing information targets with other cyberpilot librarians; we have in-flight commentary between fliers or after-flight debriefings when we discuss a particular topic or a particularly difficult search with other cyberpilot/librarians. We even chew the cyberspace fat with our colleagues by bragging about our successes ("Yes, I did find a line drawing of a wart hog online"), our unusual encounters ("Yes, the student who asked me if I thought he was schizophrenic was satisfied with the treatment information I found"), and our near misses ("I was ready to give up on biographies of famous cosmetologists when I tried one more search term and found three magazine articles"), and the new frontiers and cyberoutposts we discover ("Let me tell you about this great site I found today").

We chart our flights so that other cyberpilot/librarians (and our patrons) can find their ways to some of our favorite information destinations (hence, the booming industry in virtual reference desks and online subject guides). There's actually a cyberpilot's license on the Web. It is proposed by $R$. W. Burniske as a way to teach children not only how to use computers, e-mail, search engines, and message forums, but also to teach them about ethics and acceptable use of Web resources. ${ }^{1}$ Maylue we should consider something along the same lines for ourselves, as well as for our students.

\section{Top gun}

On my best days, when I am flying free in cyberspace, and when my computer and my imagination really get going, I can actually imagine the g-forces pushing me back into my ergonomically designed cockpit (Okay, it's really just a desk with a keyboard extension, but go with me).

And like Tom Cruise, I've learned never to leave my wing man-never leave another cyberpilot/librarian alone when there's a horde of information-hungry students around. So, if you find me in my office in my leather flight jacket and aviator glasses, call me by my cybernickname (Dewey? LC? Yahoo!? Google?) and remember that, as a library director, I have responsibilities on the flight deck as well as in cyberspace. But, on those days when I find I can navigate with the best of the best, even a library director dreams of being top gun in information cyberspace.

\section{Note}

1. See http://www.techlearning.com/db_ area/archives/WCE/archives/burniske.htm for "The Cyberpilot's License; A Modest Proposal for Educational Curricula," by R. W. Burniske and http://www.cwrl.utexas.edu/ burniske/ $\mathrm{cpl} /$ for an online prototype of Burniske's proposed license.

("Collection ... continued from page 279) responsible for getting out RFPs and handling bids), or people in the contracting company who want to focus on completing the project as rapidly and efficiently as possible, may not view collection protection as a high priority. Therefore, it is important that a library staff embarking on a renovation project understands collection protection issues and make the commitment to include a person responsible for the safety and protection of the collection at all stages of planning and implementation of the project. Failure to do so could leave the library with a nice building housing a seriously damaged collection. 